\title{
Research of the geological factors of coal deposits in the south of the Far East by electrical exploration methods
}

\author{
Nikolay Shkabarnya ${ }^{1,2^{*}}$, Grigory Shkabarnya ${ }^{2,3}$, Evgenia Nechaeva $^{2}$ and Svetlana \\ Korneeva $^{1}$ \\ ${ }^{1}$ Mining Institute of Far Easten Branch of Russian Academy of Sciences, Khabarovsk, Russia \\ ${ }^{2}$ Far Eastern Federal University, Vladivostok, Russia \\ ${ }^{3}$ V.I. Il'ichev Pacific Oceanological Institute, Far Eastern Branch, Russian Academy of Sciences, \\ Vladivostok, Russia
}

\begin{abstract}
Coal deposits in the south of the Far East are characterized by complex geological factors, which is due to the inclined occurrence the enclosing layers and coal seams, high pressure of underground water, the presence of water-bearing sandy-pebble and gravel-pebble sediments, the presence of numerous faults and various inclusions, the presence of island permafrost. In the exploration of deposits, the low efficiency of previously used electrical exploration methods, including electrical sounding and profiling, was noted. In this paper, it is shown that increasing efficiency in the solution of some mining and geological tasks is associated with the use of the electrical tomography method. This method has advantages in the conditions of weak differentiation of rock resistivity due to the high density of obtained parameters. With the use of electrical tomography, the tasks in the allocation of tectonic disturbances and coal seams uplift under quaternary sediments, estimation of the landslide slopes structures on the coal pit edges have been solved. Successful results were obtained in isolating the weathered layer of the bedrock, sandstone outcrops under the soil-vegetative layer in the upper part of the section, the bedrock surface on the deposit's flanks and the covers of effusive rocks on the surface. Keywords: coal deposit, weakened layer, weathered layer, electrical sounding, electrical tomography.
\end{abstract}

\section{Introduction}

For effective exploitation of coal deposits in the Khabarovsk and Primorye Territories, reliable information on geological factors is necessary, which can be ensured by the use of modern electrical exploration methods. The main object of coal mining in the Khabarovsk Territory is the Urgalsky coal deposit, and in the Primorsky Territory - the Bikin brown coal deposit.

The Urgalskoe deposit is characterized by relatively favorable geological factors for mining. Therefore, geophysical methods were used here in limited volumes to identify the

\footnotetext{
* Corresponding author: shkabarnya@mail.ru
} 
areas of subsidence in the worked-out space. During the studies, electrical exploration using the transient electromagnetic method and seismic exploration using the refracted and reflected wave methods (in the CDP modification) was used. As a result of the work, the structural-tectonic structure of individual sections was studied, the places of subsidence of the worked-out space in the working zones of coal seams were determined, the conditions for the occurrence of the coal-bearing complex in the $50-150 \mathrm{~m}$ depth interval were established. Complex geological factors are observed in other coal deposits of the Khabarovsk Territory: Urgal-Soloniy, Ust-Umaltinsk, Olonzhinsky. However, their studies using geophysical methods were not carried out.

In the Primorsky Territory, the study of geological factors within coal deposits was carried out in much larger volumes. This is especially true for the Bikin brown coal deposit. Here, the relatively simple plicative structure of the depression is everywhere complicated by faults and fault-shifts. Numerous coal beds lie among the host rocks of the PaleogeneNeogene, which are represented by sandstones, siltstones, argillites and carbonaceous argillites. Quaternary sediments cover with a continuous cover all ancient formations and are represented by clays, loam and sandy loam. On the local areas of the surface the covers of effusive rocks lie, represented by andesite and andesite-basalts of Paleogene age.

Coal open-casts are characterized by very complex geological and hydrogeological conditions. The water-physical and physical-mechanical properties of the rocks vary sharply both in depth and lateral. There is a large number of synclinal overlapping aquifers with an unequal water availability. The sides of the open-casts are in the water-saturated state due to unloading of the pressure waters of unopened coal seams, as well as the aquifers uncovered by the side. Throughout the entire period of mining, landslides of the sides and ledges were observed, which considerably complicate the mining operations.

Geophysical surveys of the open-casts during the 70-90s of the last century included vertical electrical sounding (VES), symmetrical and dipole electro-profiling combined with parametric boreholes. As a result of the VES curves interpretation, the thickness of Quaternary sediments and coal-bearing strata, the character of the buried surface of the basement, the boundaries of the Cenozoic sediments distribution, the patterns of changes in the physical properties of different layers of the section were established.

In the upper part of the section, sandy-argillaceous sediments and Quaternary clays were confidently distinguished by resistivities in the range of 15-40 $\Omega \mathrm{m}$, their thickness reached $30 \mathrm{~m}$. Below on the section, separate boundaries in the thickness of the Cenozoic rocks were noted, on which the approximate thicknesses of coal-bearing strata were determined. The identification and tracing of the faults according to the VES data was carried out, as a rule, from the change in the depths of coal seams occurrence.

However, it should be noted the low efficiency of previously performed electrical exploration in solving some geological tasks related to the study of coal seams, the identification and tracing of weakened layers, weathered layer of the basement and various local inclusions. First of all, this is due to the fact that most of the coal seams and weakened layers have small thickness $(5-15 \mathrm{~m})$, and the resistivity of the rocks overlaps. Therefore, in order to reduce the amount of drilling work during the study of geological factors in the open-casts, a decision was made to set the work by the method of electrical resistivity tomography (ERT). This method has advantages in conditions of weak differentiation of rocks by resistivity due to the high density of the obtained electric field parameters [1-3].

\section{Methodical research}

To effectively solve the mining and geological tasks, a priori geological and geophysical information was preliminarily studied at each section of the Bikin deposit and mathematical modeling of electric fields was carried out in the heterogeneous media conditions $[4,5]$. 
When analyzing the modeling results, the regularities of the anomalous areas of the electric field were determined, and the detection criteria for multidirectional boundaries and local heterogeneities were established, which were used at the key stage of interpretation during the formation of background geoelectrical models. Quantitative interpretation of field data was carried out by the Res2Dinv program [6] using background models. Studies ended in the formation of geoelectric sections, which, after geological interpretation, were presented in the form of geologic-geophysical sections (Figures 1, 2, 3).

Experimental electrical tomography studies at the Bikin deposit were carried out to solve various tasks. In some areas, outcrops of coal seams (with resistivities of 50-65 $\Omega \mathrm{m}$ ) under quaternary sediments among argillites (10-25 $\Omega \mathrm{m})$, siltstones $(20-40 \Omega \mathrm{m})$ and sandstones $(60-110 \Omega \mathrm{m})$ were identified and traced. The outcrops were identified at depths of 8 to 50 meters with an average thickness of 15 meters. In the study of fault zones, it has been established that the zones of crushing rocks filled with sandy-crushed-stone sediments, gravel and pebbles (and with clays and loams near the surface) are more effectively determined. Resistivity of these rocks varies in the range from 10 to $120 \Omega \mathrm{m}$, and the thickness reaches $30 \mathrm{~m}$.

ERT field works in a large volume were carried out on the landslide slopes, where the spatial position of the weakened layers was determined. Weakened layers are represented by soft-plastic clays in Quaternary sediments at depths of up to $30 \mathrm{~m}$ and very soft plastic clays of Neogene age at depths of more than $30 \mathrm{~m}$. Moreover, the latter, due to their small thickness (3-6 m), were identified (by low resistivities of 10-14 $\Omega \mathrm{m}$ ) only in conjunction with the underlying water-saturated argillic-like loam of Paleogene age, with a thickness of more than 10 meters.

Recently, for the purpose of a detailed study of the upper part of the geological section and mapping of the basement surface, investigations were carried out on the flanks of the Bikin deposit. The area of work is characterized by a shallow bedding of the basement, represented by fine-grained and very fine-grained sandstones and siliceous-argillaceous shales of the Triassic and Jurassic ages. Above the basement lie Quaternary sediments and overburden rocks.

As a result of quantitative interpretation of field materials, taking into account the geometric and electrical parameters of background models, geoelectrical sections were constructed. They confidently identified the conditions of occurrence and patterns of changes in the electrical properties of quaternary sediments, fill-up soils, and, most importantly, of the low-resistivity complex of the basement weathered layer. The roof of the complex is traced at depths from 7 to 30 meters and more. After the geological interpretation of the geoelectric sections with associating of the geoelectric and lithologic horizons the geologic-geophysical sections were compiled.

Figure 1 shows the geologic-geophysical section on one of the profiles along depression edge. It can be seen that the roof of the weathered layer is traced at depths of 10 to $25 \mathrm{~m}$. Judging by the patterns of variation in resistivity $(45-100 \Omega \mathrm{m})$, the weathered layer is the most homogeneous part of the section with highly watered segments $(45-55 \Omega \mathrm{m})$. In the central part of the section, at the depth of $45 \mathrm{~m}$ with a resistivity of $130 \Omega \mathrm{m}$, a surface of durable sandstones of the Triassic age has been identified. Sand-gravel sediments and fillup soils in the upper part of the section are distinguished by resistivity from 100 to $700 \Omega \mathrm{m}$. As can be seen, the electrical properties of the upper part change sharply along the profile. In the areas of pickets 130 and 360, alleged tectonic faults are marked. 


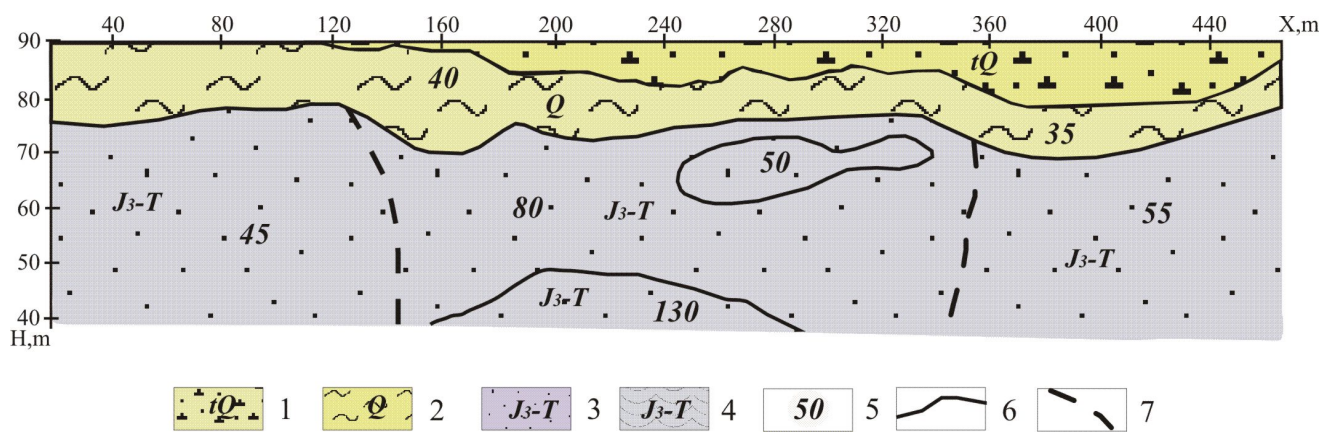

Legend: 1 - technogenic quaternary sediments, fill-up soils, sandy-gravel sediments; 2 - alluvial quaternary sediments, clays, loams; 3 - Triassic-Jurassic sandstones; 4 - Triassic-Jurassic sandstones with lenses of watering; 5 - resistivity in $\Omega \mathrm{m} ; 6$ - layer boundaries; 7 - alleged tectonic faults.

Fig. 1. Geologic-geophysical section along the basic profile in the area for tracking the weathered layer of the basement rocks.

In the course of research in several areas of the deposit, in the geological section the protrusions of the Triassic sandstones were identified and traced. These protrusions significantly complicate the mining operations. Taking into account the topicality of the such task solution, first, based on the analysis of geological and geophysical information, a background geoelectric model with a sandstone protrusion was developed (Fig. 2, a). The model parameters were used in calculating the theoretical sections of apparent resistivity for wedge-shaped media, on the basis of the analysis of which criteria for isolating such heterogeneities were determined. The main criteria were a special form of isolines of apparent resistivity with different concentrations of them over the top of the object.

Figure 2,b shows a geologic-geophysical section, on which the sandstone protrusion is marked with high resistivities (110 $\Omega \mathrm{m})$. Its top is traced among quaternary clays (14-24 $\Omega \mathrm{m})$, in the lower part - among low-resistivity (25-30 $\Omega \mathrm{m})$ argillites and siltstones of Paleogene-Neogene age. Coal seams at this depth are not found. As can be seen, the boundaries of the layers reflect the detailed structure of the geological section at the site of investigation.

In some parts of the deposit, electric tomography made it possible to identify and trace the covers of effusive rocks represented by andesites and andesite-basalts of the Paleogene age. The thickness of this rocks within the depression sometimes reaches 30 meters, which also complicates the mining operations. Figure 3 shows a geologic-geophysical section, in which under the soil-vegetable layer of low thickness, effusive rocks with resistivity of more than $70 \Omega \mathrm{m}$ and a thickness of 17 meters are distinguished. Sandy-argillaceous and slightly plastic clays of Quaternary age are shown below in the section. As can be seen, the resistivity of these sediments decreases with the depth from 50 to $14 \Omega \mathrm{m}$. 
a

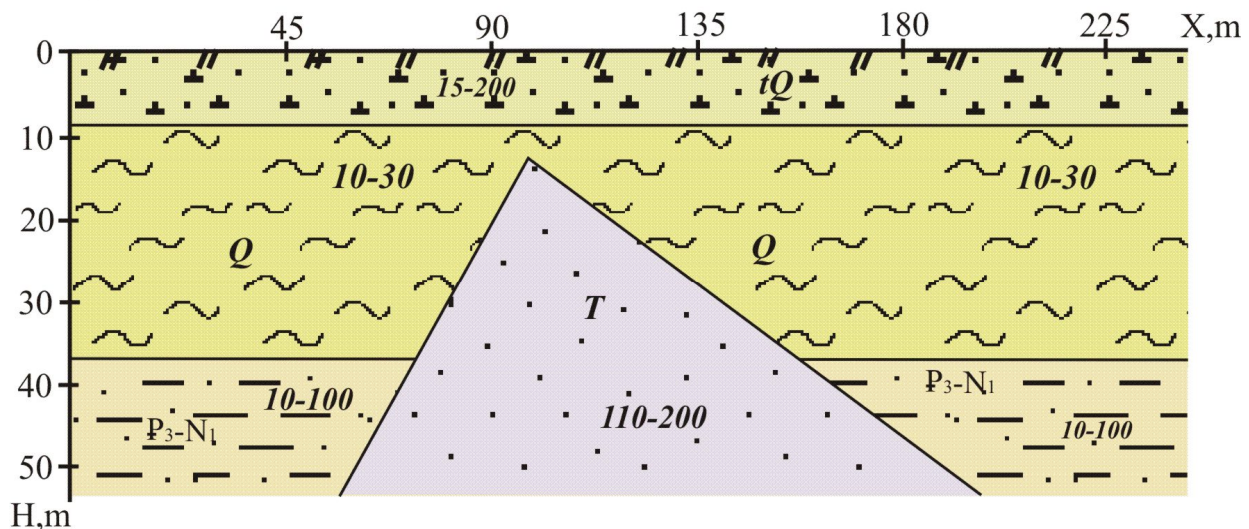

$\mathrm{b}$

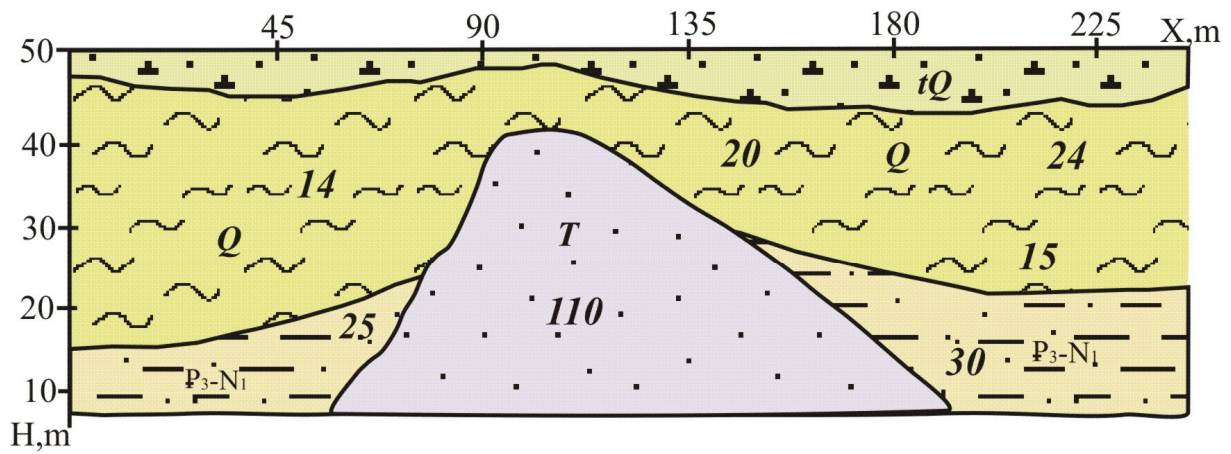

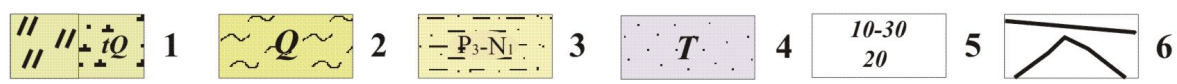

Legend: 1 - soil-vegetable layer and fill-up soils; 2 - alluvial quaternary sediments, clays, loams; 3 Paleogene-Neogene sediments, mudstones, siltstones, sandstones; 4 - durable sandstones of Triassic age; 5 - resistivity in $\Omega \mathrm{m} ; 6$ - boundaries of layers and protrusion of sandstone.

Fig. 2. Background geoelectric model (a) and geologic-geophysical section (b) at the site of tracking of the sandstone protrusion.

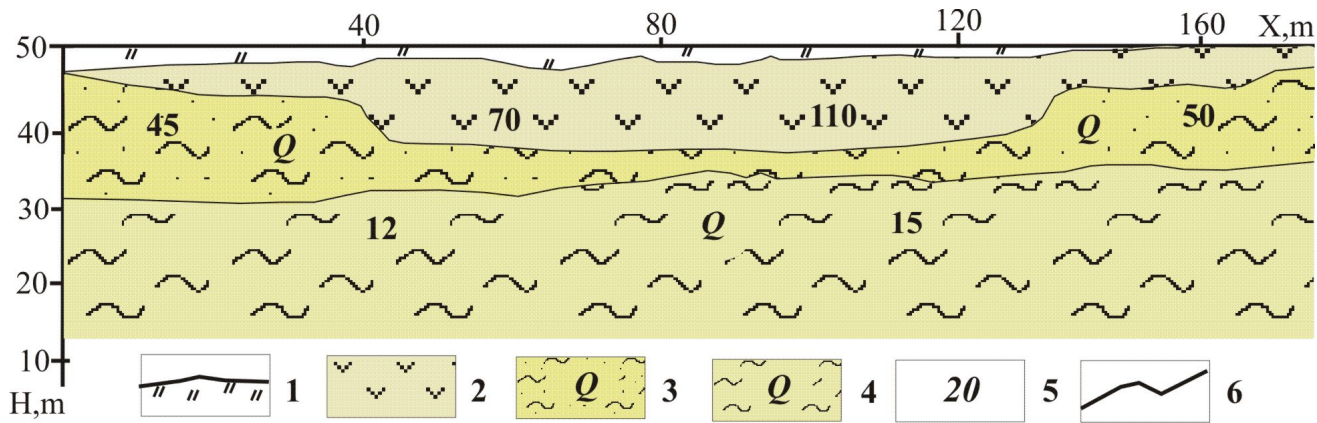

Legend: 1 - soil-vegetable layer; 2 - andesite of Paleogene age; 3 - sandy-argillaceous sediments of Quaternary age; 4 - alluvial clays of Quaternary age; 5 - resistivity in $\Omega \mathrm{m} ; 6$ - layer boundaries.

Fig. 3. Geologic-geophysical section in the area of the effusive cover. 


\section{Conclusions}

Thus, according to the research of geological factors at Bikin brown coal deposit the following main results have been obtained.

1. Previously conducted work by the method of electrical sounding (VES) and profiling (EP) allowed to determine the occurrence conditions and physical properties of quaternary deposits, and sometimes the approximate parameters of coal-bearing strata and weathering layer. However, these methods do not allow us to reliably study the geological factors of coal open pits.

2. Electrical tomography (ERT) has advantages in comparison with the VEZ and EP methods for solving mining and geological tasks in conditions of weak differentiation of rocks by resistivity, due to the high density of the obtained electric field parameters, as evidenced by the results of recent years.

3. As a result of the ERT exploration, segments of the coal seams uplift under quaternary sediments were established, weakened layers have been determined and traced. In the course of investigations on the flanks of the deposit, the thicknesses and electrical properties of quaternary deposits and fill-up soils were studied in detail, and, most importantly, the bedding conditions and properties of the basement weathered layer have been determined.

4. In several areas, by the ERT method, protrusions of durable sandstones among alluvial quaternary sediments and cover of effusive rocks have been identified and traced.

The introduction of the electrical tomography for studies of geological factors of coal deposits in the south of the Far East will contribute to their more effective mining.

\section{References}

1. Dahlin, T. Computers \& Geosciences. 27, pp.1019-1029. (2001).

2. Kenma, A., Binley, A., Ramirez, A. and Daily, W. Chemical Engineering Journal. 77, pp.11-18. (2000).

3. Rasskazov I.Yu., Shkabarnya G.N., Shkabarnya N.G. Journal of Mining Science. 49 (5), pp. 772-778. (2013).

4. Griffiths, D. H.; Barker, R. D. J. of Appl. Geophysics. 29 (3), pp. 211-226. (1993).

5. Rasskazov I.Yu., Shkabarnya G.N., Shkabarnya N.G. Journal of Mining Science. 49 (3), pp. 388-394. (2013).

6. Loke, M.H., Acworth, I. and Dahlin, T. Exploration Geophysics. 34, pp.182-187. (2003). 